\title{
Effects of dietary supplementation with the green tea polyphenol epigallocatechin-3-gallate on insulin resistance and associated metabolic risk factors: randomized controlled trial
}

\author{
A. Louise Brown ${ }^{1}$, Joan Lane ${ }^{1}$, Jacqueline Coverly ${ }^{1}$, Janice Stocks ${ }^{1}$, Sarah Jackson ${ }^{2}$, Alison Stephen ${ }^{2}$, \\ Les Bluck ${ }^{2}$, Andy Coward ${ }^{2}$ and Hilde Hendrickx ${ }^{1}$ \\ ${ }^{1}$ Unilever Corporate Research, Colworth Park, Sharnbrook, Bedfordshire MK44 1LQ, UK \\ ${ }^{2}$ MRC-Human Nutrition Research, Elsie Widdowson Laboratory, Fulbourn Road, Cambridge CB1 9NL, UK
}

(Received 15 February 2008 - Revised 5 June 2008 - Accepted 23 June 2008 - First published online 19 August 2008)

\begin{abstract}
Animal evidence indicates that green tea may modulate insulin sensitivity, with epigallocatechin-3-gallate (EGCG) proposed as a likely healthpromoting component. The purpose of this study was to investigate the effect of dietary supplementation with EGCG on insulin resistance and associated metabolic risk factors in man. Overweight or obese male subjects, aged 40-65 years, were randomly assigned to take $400 \mathrm{mg}$ capsules of EGCG $(n 46)$ or the placebo lactose ( $n$ 42), twice daily for 8 weeks. Oral glucose tolerance testing and measurement of metabolic risk factors (BMI, waist circumference, percentage body fat, blood pressure, total cholesterol, LDL-cholesterol, HDL-cholesterol, TAG) was conducted pre- and post-intervention. Mood was evaluated weekly using the University of Wales Institute of Science and Technology mood adjective checklist. EGCG treatment had no effect on insulin sensitivity, insulin secretion or glucose tolerance but did reduce diastolic blood pressure (mean change: placebo -0.058 (SE 0.75) $\mathrm{mmHg}$; EGCG -2.68 (SE 0.72$) \mathrm{mmHg} ; P=0.014$ ). No significant change in the other metabolic risk factors was observed. The EGCG group also reported feeling in a more positive mood than the placebo group across the intervention period (mean score for hedonic tone: EGCG, 29.11 (SE 0.44); placebo, 27.84 (SE 0.46); $P=0.048$ ). In conclusion, regular intake of EGCG had no effect on insulin resistance but did result in a modest reduction in diastolic blood pressure. This antihypertensive effect may contribute to some of the cardiovascular benefits associated with habitual green tea consumption. EGCG treatment also had a positive effect on mood. Further studies are needed to confirm the findings and investigate their mechanistic basis.
\end{abstract}

Obesity: Type 2 diabetes: Cardiovascular disease: Blood pressure: Catechin

Overweight and obesity is a significant public health issue. Body weight gain, especially in the abdominal region, is associated with the development of insulin resistance, a complex metabolic disorder, which precedes the development of type 2 diabetes and also represents an independent risk factor for $\mathrm{CVD}^{(1)}$.

Tea (Camellia sinensis), which is one of the most commonly consumed beverages in the world, has long been considered to possess health protective properties, particularly in relation to the prevention of CVD and cancer ${ }^{(2)}$. Recent studies suggest that regular consumption of tea polyphenols may also contribute to the prevention of type 2 diabetes ${ }^{(3)}$. Indeed, extracts of green tea ameliorate insulin resistance in high-fat-fed and high-fructose-fed rodents ${ }^{(4,5)}$ and increase insulin sensitivity in male Sprague-Dawley rats ${ }^{(6)}$. In man, regular consumption of oolong tea has been demonstrated to reduce plasma glucose levels in diabetic patients ${ }^{(7)}$ and consumption of green tea has been demonstrated to acutely improve oral glucose tolerance in healthy subjects ${ }^{(8)}$.

Epigallocatechin-3-gallate (EGCG), which is the major catechin found in green tea, has been implicated as an important bioactive molecule that may contribute to many of the health properties of tea, including effects on glucose regulation. For example, in cultured adipocytes extracts of green tea act as insulin-mimetics ${ }^{(9)}$, with EGCG being identified as the component responsible for the effect ${ }^{(10)}$. In rodent models, dietary supplementation with EGCG has been demonstrated to improve glucose tolerance and insulin sensitivity ${ }^{(11,12)}$. EGCG is also known to inhibit the activation of I-kappa kinase $^{(13-15)}$, a serine/threonine kinase implicated in the pathogenesis of insulin resistance ${ }^{(16,17)}$.

Accumulating cell and animal data suggest that regular consumption of EGCG may limit the development of insulin resistance and subsequent progression to type 2 diabetes during conditions of energy excess. However, these health benefits have yet to be substantiated in man. The purpose of the current study was to determine whether chronic dietary supplementation with EGCG would improve insulin resistance and associated metabolic risk factors (BMI, waist circumference, percentage body fat, blood pressure, total cholesterol, LDL-cholesterol, HDL-cholesterol, TAG) in non-diabetic,

Abbreviations: EGCG, epigallocatechin-3-gallate; HOMA ${ }_{\text {IR }}$, homeostasis model assessment of insulin resistance; OGTT, oral glucose tolerance test; UWIST,

University of Wales Institute of Science and Technology.

* Corresponding author: Dr A. Louise Brown, fax +44 1234 248010, email Louise.Brown@unilever.com 
overweight and obese men. A secondary objective was to investigate the effect of EGCG consumption on self-reported mood, as tea is purported to have relaxation properties and EGCG per se has been shown to possess anxiolytic activity in mice ming $^{(18,19)}$.

\section{Subjects and methods}

\section{Design and subjects}

The study was conducted between July and December 2005 at Unilever's research facility located in Bedfordshire, UK. The protocol was approved by the Colworth Science Park ethical committee and the study was conducted in accordance with the Declaration of Helsinki. Male non-smokers, aged 40-65 years, with BMI $>28$ and $<38 \mathrm{~kg} / \mathrm{m}^{2}$, fasting plasma glucose values below the diagnostic threshold for diabetes mellitus (fasting $<7.0 \mathrm{mmol} / \mathrm{l}$ ) and with no significant history of disease, current disease or on medication were recruited on to the study (Fig. 1). Subjects were drawn from an existing database reflective of the local population or recruited through an
This was a double-blind, randomized and parallel design study with groups matched for insulin resistance (homeostasis model assessment of insulin resistance, $\mathrm{HOMA}_{\mathrm{IR}}$ ) and age. The study population was randomly assigned to receive active ( $800 \mathrm{mg}$ EGCG/d) or placebo ( $800 \mathrm{mg}$ lactose/d) dietary supplements which were consumed twice daily with food, one $400 \mathrm{mg}$ capsule in the morning and another in the evening, for a period of 8 weeks. Randomization was performed by a study-independent statistician. Subjects with the highest levels of insulin resistance $\left(\mathrm{HOMA}_{\mathrm{IR}}\right.$ scores) were selected from those recruited and divided into similar pairs using a statistical clustering algorithm based upon their $\mathrm{HOMA}_{\mathrm{IR}}$ score and age. Within each pair, subjects were randomly assigned to either placebo (one of five codes) or EGCG (one of five codes) treatment codes. Subjects received their supplement packs from the study staff. To conceal treatment allocation from the study staff, supplement packs were prepared and labelled by a third-party manufacturer (DHP, Wales, UK) in accordance with the randomization list.

Subjects visited the study site, where measurements were performed, at week 0 (visit 1) and after 8 weeks of dietary supplementation (visit 2), with the last EGCG capsule being

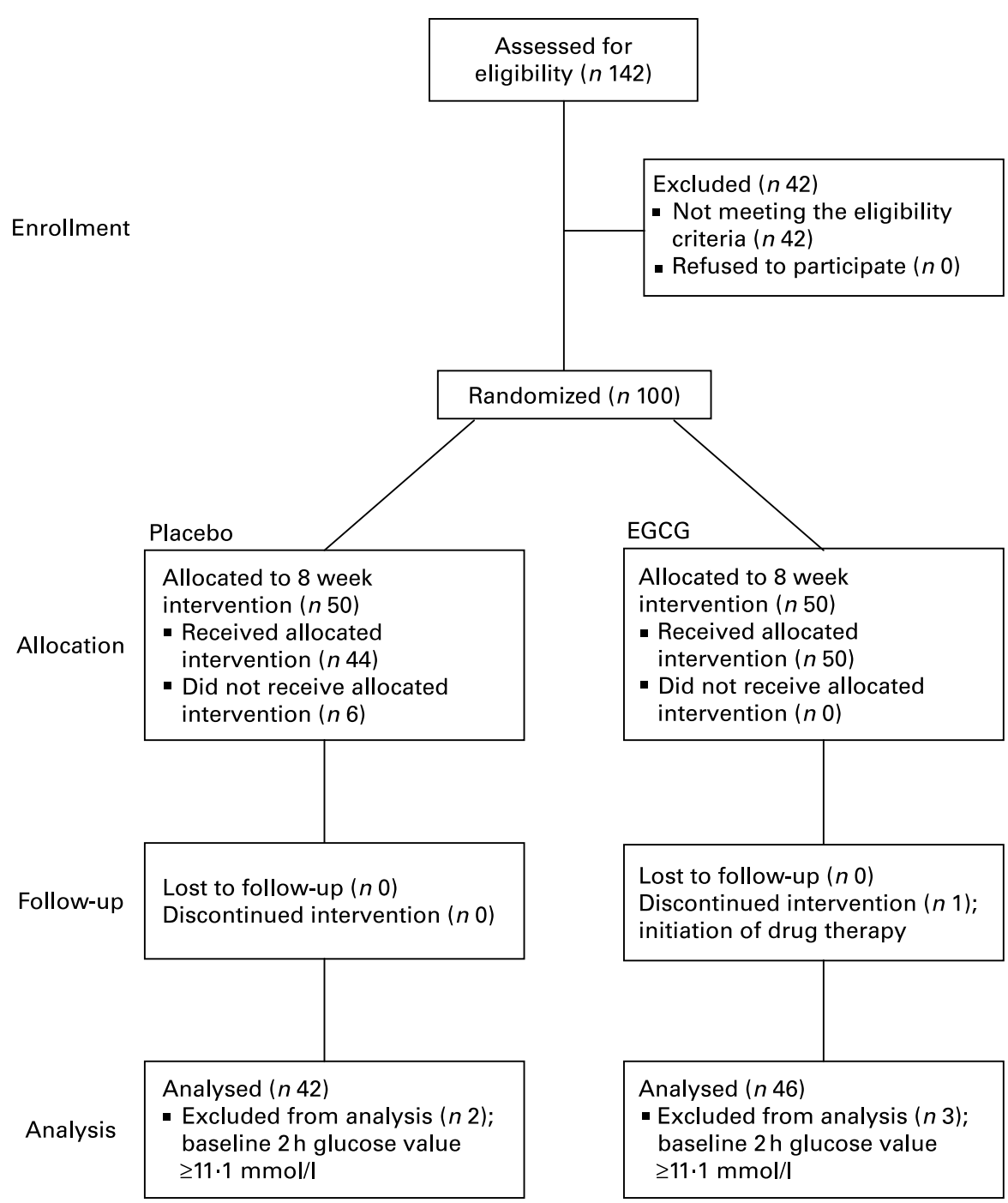

Fig. 1. Flow of participants through the phases of the study. EGCG, epigallocatechin-3-gallate. 
consumed the evening before visit 2. Urine samples (first void of the day) and information on diet and physical activity levels were collected for 7 consecutive days before each study visit. Strenuous exercise and alcohol consumption were restricted for the $24 \mathrm{~h}$ before each study visit and subjects were prohibited from eating and drinking, except for water, from 21.00 hours on the day before the visit until the various measurements were completed. During the intervention phase consumption of green tea and the taking of dietary supplements or medications known to affect glucose and lipid metabolism were prohibited, but the intake of other flavonoid-containing food products was not limited. Subjects completed health and mood questionnaires on the evening before visit 1 and once a week during the intervention period.

\section{Dietary supplements}

A commercial green tea extract (TEAVIGO ${ }^{\mathrm{TM}}$; DSM), comprising $>97 \%$ pure EGCG, was used in the study. Size 0 vegetarian gelatin capsules containing $400 \mathrm{mg}$ TEAVIGO $^{\mathrm{TM}}$ or $400 \mathrm{mg}$ lactose were prepared, by DHP, according to Good Manufacturing Practice. Capsules were weighed and sorted within $\pm 5 \%$ weight range and placed within blister packs (fourteen capsules per pack). Four blister strips were placed into a labelled carton and each subject received two cartons in their intervention kit.

\section{Anthropometric measurements}

Height $(\mathrm{cm})$, weight $(\mathrm{kg})$, waist circumference $(\mathrm{cm})$, percentage body fat and blood pressure $(\mathrm{mmHg})$ were recorded. Waist circumference was measured at the site of the smallest circumference between the rib cage and the iliac crest, with the subjects in a standing position. Percentage body fat was measured by bioelectrical impedance using a handheld device (OMRON BF 302). Blood pressure was measured manually on the upper arm using a sphygmomanometer (UA-787, $\mathrm{A}$ and D). Three measurements were taken, at $5 \mathrm{~min}$ intervals, whilst participants rested in a semi-recumbent position and with participants rested for at least $5 \mathrm{~min}$ before the first measurement. The first measurement was discarded. The second and third measurements were used to derive mean blood pressure values. Non-smoking status and alcohol abstinence were verified using Micro CO meter (Micro Medical Ltd) and AlcoMate Pro (AK Solutions) monitors, respectively. All equipment was calibrated before use.

\section{Blood sampling, oral glucose tolerance test and biochemical analysis}

Prior to ingestion of a glucose load, blood samples were taken at $-10,-5$ and $0 \mathrm{~min}$ for analysis of fasted insulin levels and at -10 and $0 \mathrm{~min}$ for analysis of fasted glucose levels. Blood samples for other measures were taken as convenient during the -10 to $0 \mathrm{~min}$ period. All blood samples were stored at $-20^{\circ} \mathrm{C}$ before analysis.

Glucose $\quad(75 \mathrm{~g})$, containing $125 \mathrm{mg} \quad \mathrm{U}-{ }^{13} \mathrm{C}$-uniformly labelled glucose, was administered as Lucozade (Glaxo SmithKline) in a volume of $394 \mathrm{ml}$. Blood samples were collected at 30, 60, 90 and $120 \mathrm{~min}$ for glucose and insulin analysis.
Glucose, cholesterol, TAG, LDL-cholesterol, HDL-cholesterol and HbA1c analysis was performed using an $\mathrm{ABX}$ Pentra 400 and assay systems supplied by Horiba ABX. Insulin analysis was performed by time-resolved fluorescence immunoassay (product code B080-101; Perkin Elmer, MA, USA) on an AutoDelfia (Perkin Elmer) automated analyser. All assays were performed in accordance with the manufacturer's instructions.

Steady-state measures of insulin sensitivity $\left(\mathrm{HOMA}_{\mathrm{IR}}\right)$ and insulin secretion $\left(\mathrm{HOMA}_{\% \mathrm{~B}}\right.$ ) were derived from mean fasting plasma glucose and mean fasting plasma insulin values as described by Matthews et al. ${ }^{(20)}$. Non-steady-state measures of insulin sensitivity $\left(\right.$ OGTT $\left._{\text {ISI }}\right)$ and insulin secretion $\left(\right.$ OGTT $\left._{\text {Insulinogenic index }}\right)$ were derived from the oral glucose tolerance test (OGTT) according to Matsuda \& DeFronzo ${ }^{(21)}$ and Phillips et al. ${ }^{(2)}$, respectively. The total area under the curve for plasma glucose was calculated using the trapezoid method where the interpolation between two adjacent observed points is a straight line. The area under the curve was only calculated if plasma glucose values were available at all time-points.

\section{Measurement of physical activity and diet}

Physical activity was measured by an accelerometer (ActiWatch $^{\mathrm{TM}}$; Cambridge Neurotechnology Ltd) worn on the non-dominant arm at the wrist and was defined as the average activity counts per epoch for the wake period (average wake movement). Data were recorded at $1 \mathrm{~min}$ epochs and processed using the software (version 5.32) supplied by the manufacturer.

Dietary information was collected in $7 \mathrm{~d}$ diaries, coded using DIDO (Diet In Data Out) ${ }^{(23)}$ and analysed using a program based on McCance and Widdowson's The Composition of Foods and supplements ${ }^{(24)}$.

\section{Health and mood questionnaires}

Mood was assessed using the University of Wales Institute of Science and Technology (UWIST) mood adjective checklist which measures dimensions of energetic arousal, tense arousal, hedonic tone and general arousal ${ }^{(25)}$. General health was evaluated using a modified version of the gastrointestinal symptom checklist developed by Svedlund et al. ${ }^{(26)}$. The questionnaire was reworded by study staff using simple non-technical terms and additional questions were added to evaluate the frequency of occurrence of common physical symptoms and sensations.

\section{Statistical analysis}

The primary end-points (insulin sensitivity, insulin secretion and glucose tolerance measures derived from the OGTT) were analysed by mixed model analysis of covariance according to a pre-established analysis plan. The variables analysed were change from baseline, with baseline included in the model as a covariate. Subject was included as a random effect and the treatment group as a fixed effect. To control for potential confounders further analysis was performed, in which a number of additional covariates (alcohol consumption (g alcohol), diet ( $\mathrm{g}$ carbohydrate, $\mathrm{g}$ fat, $\mathrm{g}$ protein, total estimated energy in $\mathrm{kJ}$ ), physical activity (average wake 
movement, counts/min) and body weight change) were included and retained in the model if significant at the $10 \%$ level. Additional end-points were analysed using a similar approach. For UWIST score data week number was included as an extra repeated measures term. Data are represented as mean and standard deviation unless stated otherwise. Statistical analysis was performed with SAS statistical software version 9.1.3 (SAS Institute Inc., Cary, NC, USA). Significance was set at $P \leq 0.05$ (two-sided).

\section{Results}

Data were analysed on a per-protocol basis, with subject exclusion occurring before release of the double-blind procedure. There were 100 subjects entered on to the study. Six subjects did not receive their allocated intervention as they failed to attend study visit 1 because of work commitments or due to moving out of the area. Five subjects with suspected diabetes mellitus $(2 \mathrm{~h}$ plasma glucose values $\geq 11.1 \mathrm{mmol} / \mathrm{l}$ ) at baseline were excluded, as $\mathrm{HOMA}_{\mathrm{IR}}$ has been reported to provide a poor estimate of insulin resistance in diabetic patients ${ }^{(27)}$ and a further subject was discontinued from the intervention because of initiation of drug therapy.
Consequently, the data reported here are for eighty-eight subjects (Fig. 1).

To monitor compliance subjects were required to return all packaging and unused capsules. Each subject received 112 capsules and on average 3.2 (SD 4.5) capsules per subject (placebo, 4.0 (SD 5.8); EGCG, 2.4 (SD 2.7)) were returned, indicating that $>95 \%$ of doses were taken. No significant differences between the EGCG or placebo groups were detected for any of the assessed gastrointestinal and general health parameters (data not shown).

Baseline characteristics for the placebo and EGCG groups are shown in Table 1. Except for HbA1c, which was higher in the EGCG group $(P=0.043)$ and fat intake, which was higher in the placebo group $(P=0.040)$, no significant differences between any of the group means were detected at baseline (Table 1). It was found that $57.1 \%$ of the placebo group and $58.7 \%$ of the EGCG group were classified as obese (BMI $\geq 30)$. A subset of subjects also manifested with glucose intolerance: 19.5 and $20.0 \%$ with impaired fasting glucose; 7.3 and $6.7 \%$ with impaired glucose tolerance; 4.9 and $8.9 \%$ with combined impairments (impaired fasting glucose and impaired glucose tolerance), for placebo and EGCG groups, respectively, categories being defined

Table 1. Baseline characteristics of the study population

(Mean values and standard deviations)

\begin{tabular}{|c|c|c|c|c|c|c|}
\hline & \multicolumn{3}{|c|}{ Placebo } & \multicolumn{3}{|c|}{ EGCG } \\
\hline & $n$ & Mean & SD & $n$ & Mean & SD \\
\hline Age (years) & 42 & $50 \cdot 57$ & 6.48 & 46 & $52 \cdot 15$ & 6.43 \\
\hline \multicolumn{7}{|l|}{ Insulin sensitivity } \\
\hline Fasting insulin (mU/l) & 42 & $10 \cdot 74$ & 4.52 & 46 & 11.06 & 4.95 \\
\hline $\mathrm{HOMA}_{\mathrm{IR}}$ & 42 & 2.56 & $1 \cdot 17$ & 46 & 2.66 & 1.25 \\
\hline $\mathrm{OGTT}_{\mid \mathrm{SI}}$ & 33 & $69 \cdot 76$ & $32 \cdot 02$ & 37 & 63.47 & $30 \cdot 45$ \\
\hline \multicolumn{7}{|l|}{ Insulin secretion } \\
\hline HOMA\%в & 42 & $122 \cdot 07$ & 51.60 & 46 & $123 \cdot 11$ & 54.41 \\
\hline OGTT $_{\text {Insulinogenic index }}$ & 38 & 21.50 & $12 \cdot 62$ & 42 & 26.03 & 33.19 \\
\hline \multicolumn{7}{|l|}{ Glucose tolerance } \\
\hline Fasting glucose $(\mathrm{mmol} / \mathrm{l})$ & 42 & $5 \cdot 31$ & 0.43 & 46 & $5 \cdot 37$ & 0.51 \\
\hline $\mathrm{OGTT}_{2 \text { h glucose }}(\mathrm{mmol} / \mathrm{l})$ & 41 & 5.78 & 1.49 & 46 & 5.94 & 1.68 \\
\hline $\mathrm{OGTT}_{\text {Total AUC glucose }}(\mathrm{mmol} \mathrm{h} / \mathrm{l})$ & 33 & $14 \cdot 59$ & $3 \cdot 20$ & 37 & $15 \cdot 46$ & 3.01 \\
\hline $\mathrm{HbA1c}(\%)$ & 42 & $5 \cdot 12$ & 0.32 & 45 & $5 \cdot 28^{*}$ & 0.43 \\
\hline \multicolumn{7}{|l|}{ Metabolic risk factors } \\
\hline BMI $\left(\mathrm{kg} / \mathrm{m}^{2}\right)$ & 42 & $30 \cdot 96$ & 2.45 & 46 & $31 \cdot 21$ & $2 \cdot 80$ \\
\hline Waist circumference (cm) & 42 & $106 \cdot 14$ & $7 \cdot 34$ & 46 & $107 \cdot 04$ & 8.85 \\
\hline Body fat $(\%)$ & 41 & $28 \cdot 21$ & $2 \cdot 81$ & 46 & 29.52 & 3.98 \\
\hline Systolic blood pressure $(\mathrm{mmHg})$ & 42 & $138 \cdot 15$ & $18 \cdot 23$ & 46 & $136 \cdot 16$ & 13.00 \\
\hline Diastolic blood pressure $(\mathrm{mmHg})$ & 42 & $87 \cdot 17$ & $9 \cdot 22$ & 46 & $86 \cdot 67$ & $7 \cdot 26$ \\
\hline Total cholesterol $(\mathrm{mmol} / \mathrm{l})$ & 42 & $5 \cdot 39$ & 1.06 & 46 & $5 \cdot 64$ & 1.09 \\
\hline HDL-cholesterol (mmol/l) & 42 & $1 \cdot 17$ & 0.20 & 46 & 1.20 & 0.24 \\
\hline LDL-cholesterol (mmol/l) & 42 & 3.51 & 0.86 & 46 & 3.65 & 1.03 \\
\hline TAG $(\mathrm{mmol} / \mathrm{l})$ & 42 & 1.75 & 0.94 & 46 & 1.69 & 0.81 \\
\hline \multicolumn{7}{|l|}{ Diet and physical activity } \\
\hline Alcohol $(\mathrm{g} / \mathrm{d})$ & 42 & 21.08 & $18 \cdot 01$ & 45 & 24.49 & 23.32 \\
\hline Carbohydrate (g/d) & 42 & $268 \cdot 26$ & 68.57 & 45 & $262 \cdot 36$ & $65 \cdot 29$ \\
\hline Fat $(g / d)$ & 42 & $103 \cdot 13$ & 24.89 & 45 & $92 \cdot 00^{*}$ & 24.87 \\
\hline Protein $(\mathrm{g} / \mathrm{d})$ & 42 & 98.43 & $20 \cdot 26$ & 45 & $94 \cdot 37$ & $18 \cdot 62$ \\
\hline Total estimated energy & 42 & & & 45 & & \\
\hline $\mathrm{kJ} / \mathrm{d}$ & & $10338 \cdot 29$ & $2076 \cdot 94$ & & 9852.65 & $1767 \cdot 87$ \\
\hline $\mathrm{kcal} / \mathrm{d}$ & & $2470 \cdot 91$ & 496.40 & & 2354.84 & 422.53 \\
\hline Average Wake Movement (counts/min) & 34 & 291.36 & 97.79 & 41 & 318.42 & $79 \cdot 32$ \\
\hline
\end{tabular}

AUC, area under the curve; EGCG, epigallocatechin-3-gallate; $\mathrm{HOMA}_{\mathrm{IR}}$, homeostasis model assessment of insulin resistance; $\mathrm{HOMA}_{\mathrm{B}}$, homeostasis model assessment of pancreatic $\beta$-cell function; OGTT, oral glucose tolerance test.

Mean values were significantly different from those of the placebo: ${ }^{*} P \leq 0.05$. 
according to recent American Diabetes Association guidelines ${ }^{(28)}$. The presence of obesity and glucose intolerance did not differ between the groups.

To evaluate the effect of dietary intervention, change from baseline at week 8 was compared between the placebo and EGCG groups for each parameter. No significant differences were detected between the two groups for any of the insulin sensitivity, insulin secretion or glucose tolerance measures (Table 2). However, EGCG treatment was found to reduce diastolic blood pressure $(P=0 \cdot 014)$ (Table 2; Fig. 2). Although not significant, a trend towards a reduction in systolic blood pressure $(P=0.096)$ was also noted. Importantly, the blood pressure values for the two groups did not differ significantly at baseline (Table 1). The EGCG intervention had no significant effect on any of the other metabolic risk factors measured (Table 2). Over the course of the intervention no significant change in dietary intake measures ( $\mathrm{g}$ alcohol/carbohydrate/ fat/protein or total estimated energy in $\mathrm{kJ}$ ) was detected (data not shown).

The EGCG intervention also had an effect on mood, as measured by the UWIST mood adjective checklist (Fig. 3). Across the 8-week period, the EGCG group scored higher on hedonic tone than the placebo group (29.11 (SE 0.44) v. 27.84 (SE 0.46), $P=0.048$ ). Although not quite reaching significance the EGCG group also scored lower on tense arousal compared to the placebo group (11.06 (SE 0.47) v. 12.33 (SE 0.45), $P=0.056$ ). Importantly, the baseline scores for both components (tense arousal, placebo 11.83 (SD 3.99), EGCG 11.29 (SD 3.06); hedonic tone, placebo 29.25 (SD 3.72), EGCG 29.10 (SD 3.68)) were virtually the same for the EGCG and placebo groups. Results for energetic arousal and general arousal did not differ significantly between the two groups.

To account for potential confounders and to test the robustness of the results we conducted multivariate analysis. Except

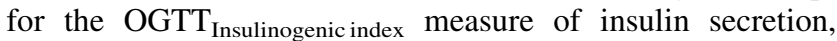
inclusion in the model of additional covariates [alcohol consumption ( $\mathrm{g}$ alcohol), diet ( $\mathrm{g}$ carbohydrate, $\mathrm{g}$ fat, $\mathrm{g}$ protein, total estimated energy in $\mathrm{kJ}$ ), physical activity (average wake movement, counts/min) and body weight change] did not substantially change the findings (data not shown). A significant difference $(P=0 \cdot 048)$ between the placebo and EGCG groups was detected for OGTT Insulinogenic index $_{\text {(mean change: }}$ placebo 11.22 (SE 4.02), EGCG - 0.25 (SE 3.97)). However, after removal from the analysis of one subject in the placebo

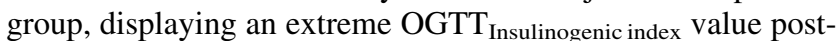
intervention but not at baseline, the difference was no longer significant.

\section{Discussion}

The effect of EGCG, on insulin resistance and associated metabolic risk factors, was assessed in a population of middle-aged, overweight and obese men. Subjects consumed $400 \mathrm{mg}$ EGCG twice daily, which is comparable to drinking ten cups per day of moderate-strength green tea prepared from leaves with a relatively high EGCG content ${ }^{(29)}$. At the end of the 8-week treatment period no change in insulin sensitivity, insulin secretion, glucose tolerance, BMI, waist circumference, percentage body fat, total cholesterol, LDL-cholesterol, HDL-cholesterol, TAG or

Table 2. Effect of dietary supplementation on metabolic variables and risk factors, data shown as change from baseline at week $8 \dagger$ (Mean values with their standard errors)

\begin{tabular}{|c|c|c|c|c|c|c|}
\hline & \multicolumn{3}{|c|}{ Placebo } & \multicolumn{3}{|c|}{ EGCG } \\
\hline & $n$ & Least square mean & SE & $n$ & Least square mean & SE \\
\hline \multicolumn{7}{|l|}{ Insulin sensitivity } \\
\hline Fasting insulin (mU/l) & 42 & -0.16 & 0.54 & 46 & -0.088 & 0.52 \\
\hline $\mathrm{HOMA}_{\mathrm{IR}}$ & 42 & 0.011 & $0 \cdot 14$ & 46 & 0.011 & $0 \cdot 14$ \\
\hline $\mathrm{OGTT}_{|S|}$ & 28 & 4.05 & $4 \cdot 61$ & 34 & 4.83 & $4 \cdot 18$ \\
\hline \multicolumn{7}{|l|}{ Insulin secretion } \\
\hline $\mathrm{HOMA}_{\% \mathrm{~B}}$ & 42 & $-5 \cdot 55$ & $5 \cdot 94$ & 46 & -3.86 & $5 \cdot 67$ \\
\hline OGTT Insulinogenic index & 36 & $10 \cdot 03$ & $4 \cdot 15$ & 38 & 1.76 & 4.04 \\
\hline \multicolumn{7}{|l|}{ Glucose tolerance } \\
\hline Fasting glucose $(\mathrm{mmol} / \mathrm{l})$ & 42 & 0.051 & 0.049 & 46 & 0.057 & 0.047 \\
\hline $\mathrm{OGTT}_{2 \text { h glucose }}(\mathrm{mmol} / \mathrm{l})$ & 40 & -0.029 & $0 \cdot 16$ & 45 & -0.28 & 0.15 \\
\hline OGTT $_{\text {Total AUC glucose }}(\mathrm{mmol} \mathrm{h} / \mathrm{l})$ & 28 & -0.86 & 0.31 & 34 & -0.35 & 0.28 \\
\hline $\mathrm{HbA} 1 \mathrm{c}(\%)$ & 42 & 0.099 & 0.053 & 43 & 0.029 & 0.053 \\
\hline \multicolumn{7}{|l|}{ Metabolic risk factors } \\
\hline $\operatorname{BMI}\left(\mathrm{kg} / \mathrm{m}^{2}\right)$ & 42 & 0.058 & 0.076 & 46 & -0.0042 & 0.072 \\
\hline Waist circumference $(\mathrm{cm})$ & 42 & -0.39 & 0.46 & 46 & -0.74 & 0.44 \\
\hline Body fat $(\%)$ & 41 & -0.0021 & $0 \cdot 14$ & 46 & -0.050 & $0 \cdot 13$ \\
\hline Systolic blood pressure (mmHg) & 42 & -0.26 & 1.11 & 46 & $-2 \cdot 85$ & 1.06 \\
\hline Diastolic blood pressure $(\mathrm{mmHg})$ & 42 & -0.058 & 0.75 & 46 & $-2 \cdot 68^{\star}$ & 0.72 \\
\hline Total cholesterol $(\mathrm{mmol} / \mathrm{l})$ & 42 & 0.09 & 0.11 & 46 & 0.086 & $0 \cdot 10$ \\
\hline HDL-cholesterol (mmol/l) & 42 & 0.031 & 0.023 & 46 & -0.0062 & 0.022 \\
\hline LDL-cholesterol (mmol/l) & 42 & -0.12 & 0.087 & 46 & 0.012 & 0.083 \\
\hline TAG $(\mathrm{mmol} / \mathrm{l})$ & 42 & -0.095 & $0 \cdot 13$ & 46 & 0.19 & 0.12 \\
\hline
\end{tabular}

EGCG, epigallocatechin-3-gallate; $\mathrm{HOMA}_{\mathrm{IR}}$, homeostasis model assessment of insulin resistance; $\mathrm{HOMA} \% \mathrm{~B}$, homeostasis model assessment of pancreatic $\beta$-cell function; OGTT, oral glucose tolerance test.

Value was significantly different from that of the placebo: ${ }^{\star} P \leq 0.05$ (mixed model analysis of covariance, baseline as a covariate, subject as a random effect and treatment group as a fixed effect).

†For details of subjects and procedures, see Table 1 and Subjects and methods section. 


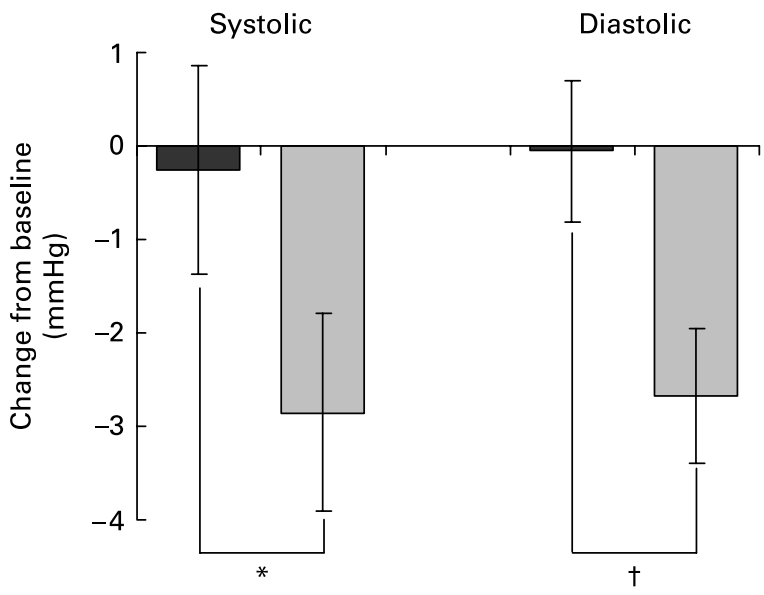

Fig. 2. Mean blood pressure change after 8 weeks of dietary supplementation ( $\square$, placebo, $n 42 ; \square$, EGCG, $n$ 46). Mixed model analysis of covariance was used with baseline included as a covariate, subject as a random effect and treatment group as a fixed effect. Values are least square means with their standard errors depicted by vertical bars. Values were significantly different: ${ }^{\star} P=0.096, \dagger P=0.014$.

systolic blood pressure was detected. However, diastolic blood pressure was found to be reduced and mood improved.

Dietary supplementation with green tea or EGCG is known to improve insulin sensitivity and oral glucose tolerance in rodents ${ }^{(4-6,11,12)}$. However, a similar effect was not observed in this human study. A number of other human intervention studies examining the effect of green tea on insulin resistance have recently been reported. In these studies a daily intake of $500 \mathrm{mg}$ green tea catechins for 2 months ${ }^{(30,31)}, 540 \mathrm{mg}$ EGCG for 3 months ${ }^{(32)}$ and $9 \mathrm{~g}$ green tea for 4 weeks ${ }^{(33)}$ was investigated. Similar to the present findings, consumption of green tea had no effect on insulin resistance, as determined by measures of $\mathrm{HOMA}_{\mathrm{IR}}$ or fasted serum insulin ${ }^{(30-33)}$; although, Fukino et al. ${ }^{(31)}$ did observe a small but significant reduction in HbA1c. The discrepancy in findings between the human and animal studies may reflect species-specific differences. Alternatively, it may result from the lower dose of EGCG/ green tea employed here and in the other human studies

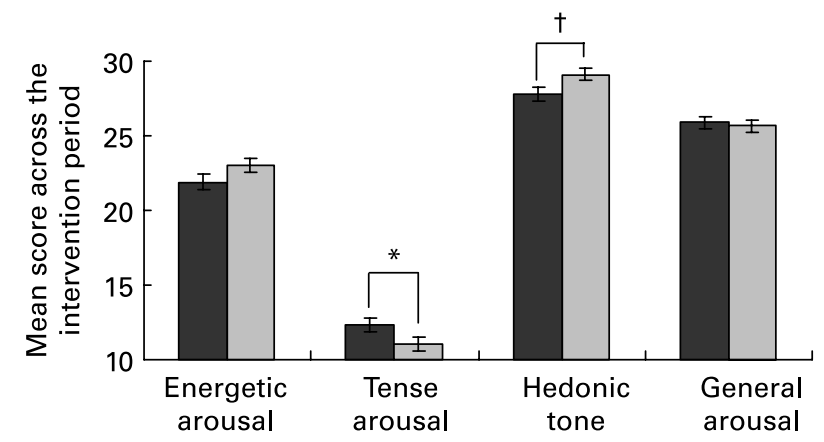

Fig. 3. Effect of dietary supplementation on mood, as measured by the University of Wales Institute of Science and Technology (UWIST) mood adjective checklist ( $\square$, placebo, $n$ 42; $\square$, EGCG, $n$ 46). UWIST data were analysed by mixed model repeated measures analysis of covariance, with baseline included as a covariate, subject as a random effect, treatment group as a fixed effect and week number as a repeated measures term. Values are least square means with their standard errors depicted by vertical bars. No baseline differences $(P \leq 0.05)$ were detected between the two groups. Values were significantly different: ${ }^{\star} P=0.056, \dagger P=0.048$. compared to the dose tested in rodents. Indeed, the oral bioavailability of EGCG is relatively low in man. Based on the results of pharmacokinetic studies conducted by ourselves (unpublished data) and reported by others ${ }^{(34)}$, we would anticipate that a peak plasma concentration of EGCG in the region of $1 \mu \mathrm{M}$ would result from the dose of EGCG we administered. In contrast, in vitro studies suggest that much higher $(25-100 \mu \mathrm{M})$ concentrations of EGCG may be required to mimic the metabolic actions of insulin ${ }^{(35)}$.

Even though no effect on insulin resistance was observed, diet supplementation with EGCG was found to reduce diastolic blood pressure by approximately $2.5 \mathrm{mmHg}$. Although a modest reduction, this is clinically significant at the population level. Indeed, a reduction in diastolic blood pressure of $2 \mathrm{mmHg}$ has been calculated to reduce hypertension by $17 \%$ and reduce the risk of stroke and CHD by 15 and $6 \%$, respectively ${ }^{(36)}$. Consistent with the effect of EGCG on diastolic blood pressure observed here, habitual consumption of green tea has been associated with a reduced risk of hypertension in a Chinese population ${ }^{(37)}$. Also, dietary supplementation with green tea, and more recently EGCG, has been shown to prevent blood pressure increases in rodents ${ }^{(11,38,39)}$.

Although not investigated in the present study, the mechanism by which EGCG influences blood pressure may be linked to an impact on the endothelial cell and production of vasoconstrictors and vasodilators which subsequently impact on smooth muscle cell function and vascular tone. Indeed, EGCG induces dose-dependent vasodilation in pre-contracted rat aortic rings ${ }^{(40)}$ and in mesenteric vascular beds isolated from spontaneously hypertensive rats ${ }^{(11)}$, effects being elicited at concentrations as low as $1 \mu \mathrm{M}$, albeit weakly. In cultured endothelial cells EGCG has been demonstrated to activate endothelial nitric oxide synthase and stimulate production of NO, which is a potent vasodilator ${ }^{(40,41)}$. The acute actions of EGCG to stimulate endothelial production of NO are indicated to be via the phosphotidylinositol-3-kinase/Akt pathway $^{(40,42)}$ and may, in part, be the result of the inhibitory effect of EGCG on I-kappa kinase activity ${ }^{(13,43-45)}$. EGCG may also influence NO production by modulating other signalling pathways ${ }^{(46)}$. In man, improvements in brachial artery flow-mediated dilation have been observed in coronary artery disease patients $2 \mathrm{~h}$ after EGCG administration ${ }^{(47)}$. Additionally, in male smokers consumption of green tea has been found to promote endothelial-dependent vasorelaxation $^{(48,49)}$. Other flavonoids have similarly been shown to influence vascular function in $\operatorname{man}^{(50)}$.

A further observation from the present study was that dietary supplementation with EGCG had a beneficial effect on mood. Over the intervention period, subjects in the EGCG group reported feeling in a more positive mood compared to the placebo group and a tendency to feel less tense. This was in the absence of any baseline differences between the two groups. The present results suggest that EGCG treatment may have impacted central nervous system function. In mice, EGCG has been shown to be distributed in the brain after oral administration ${ }^{(51)}$. In addition, flavonoids have affinities for the benzodiazepine binding sites of $\gamma$-aminobutyric acid receptors $\left(\mathrm{GABA}_{\mathrm{A}}\right)^{(52)}$. $\gamma$-Aminobutyric acid is the principal inhibitory system in the brain mediating neurotransmitter receptor systems that regulate anxiety. In mice, both intracerebroventricular and oral administration of 
EGCG produce behavioural effects reflecting anxiolytic activity $^{(18,19)}$. The present study suggests that EGCG may have similar anxiolytic and sedative effects in man. Indeed, in man regular tea consumption results in lower post-stress cortisol levels and greater subjective relaxation, an effect that could be partially mediated through the effect of flavonoids on $\mathrm{GABA}_{\mathrm{A}}$ receptors ${ }^{(53)}$.

The present study has a number of limitations that do need to be acknowledged. The sample size was relatively small and a change in metabolic variables in response to the EGCG intervention may not have been detected if the effect size were small. Although overweight or obese and displaying a marked degree of insulin resistance, our study population was largely normoglycaemic. It is possible that significant glucose dysregulation may be required before the metabolic effects of regular EGCG consumption manifest in man and further studies are needed to explore this possibility. However, it is worth noting that in a study conducted in type 2 diabetic patients daily consumption of $900 \mathrm{ml}$ water containing $9 \mathrm{~g}$ green tea did not influence insulin resistance, inflammation or adiponectin levels ${ }^{(32)}$. Furthermore, increases in insulin sensitivity have been demonstrated in both healthy persons and hypertensive subjects without diabetes or impaired glucose tolerance after short-term administration of dark chocolate ${ }^{(54,55)}$. With the exception of green tea, which is the primary dietary source of EGCG, the consumption of flavonoid-containing foods was not restricted during the study. Also, because of the nature of the study population the extrapolation of the present findings may be somewhat limited. Finally, it should be recognized that a relatively large number of comparisons have been performed in the present study which does increase the probability that the significant effects we report may have occurred by chance. Additional studies are therefore required to substantiate our findings.

In conclusion, diet supplementation with EGCG had no significant effect on insulin resistance or other associated metabolic risk factors, in a sample of overweight and obese men, but did reduce diastolic blood pressure. This antihypertensive effect may contribute to some of the cardiovascular benefits associated with habitual green tea consumption. Additionally, subjects in the EGCG group reported an improvement in mood compared to the placebo group, indicating that EGCG (or its metabolites) may also have anxiolytic effects in man. Further studies are now needed to confirm the present findings and to explore their mechanistic basis.

\section{Acknowledgements}

We acknowledge Ms Anna Gent and Ms Louise McKenna for technical support and Dr Oscar Franco for helpful suggestions during preparation of the manuscript. A. L. B. was responsible for the concept, data interpretation and preparation of the manuscript. J. L. and J. C. were responsible for conducting the study and for data collection and management. J. S. was responsible for data analysis. H. H. was involved in data interpretation. All authors contributed to the study design. The manuscript was critically reviewed by A. S., H. H., J. C., J. L., J. S., L. B. and S. J. The authors A. L. B., H. H., J. C., J. L. and J. S. are all employed by Unilever Corporate Research, which is a division of Unilever Plc, a company which has a significant commercial interest in tea. The authors S. J., L. B., A. S. and A. C. have no conflict of interest in relation to this study.

\section{References}

1. Lebovitz HE (2006) Insulin resistance - a common link between type 2 diabetes and cardiovascular disease. Diabetes Obes Metab 8, 237-249.

2. Kahn N \& Mukhtar H (2007) Tea polyphenols for health promotion. Life Sci 81, 519-533.

3. Kao YH, Chang HH, Lee MJ \& Chen CL (2006) Tea, obesity, and diabetes. Mol Nutr Food Res 50, 188-210.

4. Murase T, Nagasawa A, Suzuki J, Hase T \& Tokimitsu I (2002) Beneficial effects of tea catechins on diet-induced obesity: stimulation of lipid catabolism in the liver. Int $J$ Obes 26, 1459-1464.

5. Wu LY, Juan CC, Hwang LS, Hsu YP, Ho PH \& Ho LT (2004) Green tea supplementation ameliorates insulin resistance and increases glucose transporter IV content in a fructose-fed rat model. Eur J Nutr 43, 116-124.

6. Wu LY, Juan CC, Ho LT, Hsu YP \& Hwang LS (2004) Effect of green tea supplementation on insulin sensitivity in SpragueDawley rats. J Agric Food Chem 52, 643-648.

7. Hosoda K, Wang MF, Liao ML, Chuang CK, Iha M, Clevidence B \& Yamamoto S (2003) Antihyperglycentic effect of oolong tea in type 2 diabetes. Diabetes Care 26, 1714-1718.

8. Tsuneki H, Ishizuka M, Terasawa M, Wu JB, Sasaoka T \& Kimura I (2004) Effect of green tea on blood glucose levels and serum proteomic patterns in diabetic $(\mathrm{db} / \mathrm{db})$ mice and on glucose metabolism in healthy humans. BMC Pharmacol 4, 18.

9. Broadhurst CL, Polansky MM \& Anderson RA (2000) Insulinlike biological activity of culinary and medicinal plant aqueous extracts in vitro. J Agric Food Chem 48, 849-852.

10. Anderson RA \& Polansky MM (2002) Tea enhances insulin activity. J Agric Food Chem 50, 7182-7186.

11. Potenza MA, Marasciulo FL, Tarquinio M, Tiravanti E, Colantuono G, Federici A, Kim JA, Quon MJ \& Montagnani M (2007) EGCG, a green tea polyphenol, improves endothelial function and insulin sensitivity, reduces blood pressure, and protects against myocardial I/R injury in SHR. Am J Physiol Endocrinol Metab 292, E1378-E1387.

12. Wolfram S, Raederstorff D, Preller M, Wang Y, Teixeira SR, Riegger C \& Weber P (2006) Epigallocatechin gallate supplementation alleviates diabetes in rodents. $J$ Nutr 136, 2512-2518.

13. Chen PC, Wheeler DS, Malhotra V, Odoms K, Denenberg AG \& Wong HR (2002) A green tea-derived polyphenol, epigallocatechin-3-gallate, inhibits I kappa B kinase activation and IL-8 gene expression in respiratory epithelium. Inflammation 26, 233-241.

14. Pan MH, Lin-Shiau SY, Ho CT, Lin JH \& Lin JK (2000) Suppression of lipopolysaccharide-induced nuclear factor-kappa B activity by theaflavin-3, $3^{\prime}$-digallate from black tea and other polyphenols through down-regulation of I kappa B kinase activity in macrophages. Biochem Pharmacol 59, 357-367.

15. Yang FJ, Oz HS, Barve S, De Villiers WJS, McClain CJ \& Varilek GW (2001) The green tea polyphenol (-)-epigallocatechin-3-gallate blocks nuclear factor-kappa B activation by inhibiting I kappa B kinase activity in the intestinal epithelial cell line IEC-6. Mol Pharmacol 60, 528-533.

16. Shoelson SE, Lee J \& Yuan M (2003) Inflammation and the IKK beta/I kappa B/NF-kappa B axis in obesity- and dietinduced insulin resistance. Int J Obes 27, S49-S52. 
17. Tamura Y, Ogihara T, Uchida T, et al. (2007) Amelioration of glucose tolerance by hepatic inhibition of nuclear factor kappa $\mathrm{B}$ in $\mathrm{db} / \mathrm{db}$ mice. Diabetologia 50, 131-141.

18. Adachi N, Tomonaga S, Tachibana T, Denbow DM \& Furuse M (2006) (-)-Epigallocatechin gallate attenuates acute stress responses through GABAergic system in the brain. Eur J Pharmacol 531, 171-175.

19. Vignes M, Maurice T, Lante F, Nedjar M, Thethi K, Guiramand J \& Recasens M (2006) Anxiolytic properties of green tea polyphenol (-)-epigallocatechin gallate (EGCG). Brain Res 1110, $102-115$.

20. Matthews DR, Hosker JP, Rudenski AS, Naylor BA, Treacher DF \& Turner RC (1985) Homeostasis model assessment insulin resistance and beta-cell function from fasting plasmaglucose and insulin concentrations in man. Diabetologia 28, 412-419.

21. Matsuda M \& DeFronzo RA (1999) Insulin sensitivity indices obtained from oral glucose tolerance testing - comparison with the euglycemic insulin clamp. Diabetes Care 22, $1462-1470$.

22. Phillips DIW, Clark PM, Hales CN \& Osmond C (1994) Understanding oral glucose-tolerance - comparison of glucose or insulin measurements during the oral glucose-tolerance test with specific measurements of insulin-resistance and insulinsecretion. Diabetes Med 11, 286-292.

23. Price GM, Paul AA, Key FB, Harter AC, Cole TJ, Day KC \& Wadsworth MEJ (1995) Measurement of diet in a large national survey: comparison of computerised and manual coding in household measures. J Hum Nutr Diet 8, 417-428.

24. Foods Standards Agency (2002) McCance and Widdowson's The Composition of Food, 6th ed. Cambridge: Royal Society of Chemistry.

25. Matthews G, Jones DM \& Chamberlain AG (1990) Refining the measurement of mood - the UWIST mood adjective checklist. Br J Psychol 81, 17-42.

26. Svedlund J, Sjodin I \& Dotevall G (1988) GSRS - a clinical rating-scale for gastrointestinal symptoms in patients with irritable bowel syndrome and peptic-ulcer disease. Digest Dis Sci 33, 129-134.

27. Laakso M (1993) How good a marker is insulin level for insulin-resistance. Am J Epidemiol 137, 959-965.

28. Genuth S, Alberti KGMM, Bennett P, et al. (2003) Follow-up report on the diagnosis of diabetes mellitus. Diabetes Care 26, 3160-3167.

29. Khokhar S \& Magnusdottir SGM (2002) Total phenol, catechin, and caffeine contents of teas commonly consumed in the United Kingdom. J Agric Food Chem 50, 565-570.

30. Fukino Y, Shimbo M, Aoki N, Okubo T \& Iso H (2005) Randomized controlled trial for an effect of green tea consumption on insulin resistance and inflammation markers. J Nutr Sci Vitaminol 51, 335-342.

31. Fukino Y, Ikeda A, Maruyama K, Aoki N, Okubo T \& Iso H (2007) Randomized controlled trial for an effect of green teaextract powder supplementation on glucose abnormalities. Eur $J$ Clin Nutr (Epublication ahead of print version 6 June 2007).

32. Chan CCW, Koo MWL, Ng EHY, Tang OS, Yeung WSB \& Ho PC (2006) Effects of Chinese green tea on weight, and hormonal and biochemical profiles in obese patients with polycystic ovary syndrome - a randomized placebo-controlled trial. J Soc Gynecol Invest 13, 63-68.

33. Ryu OH, Lee J, Lee KW, Kim HY, Seo JA, Kim SG, Kim NH, Baik SH, Choi DS \& Choi KM (2006) Effects of green tea consumption on inflammation, insulin resistance and pulse wave velocity in type 2 diabetes patients. Diabetes Res Clin Prac 71, 356-358.

34. Feng WY (2006) Metabolism of green tea catechins: an overview. Curr Drug Metab 7, 755-809.
35. Waltner-Law ME, Wang XHL, Law BK, Hall RK, Nawano M \& Granner DK (2002) Epigallocatechin gallate, a constituent of green tea, represses hepatic glucose production. $J$ Biol Chem 277, 34933-34940.

36. Cook NR, Cohen J, Hebert PR, Taylor JO \& Hennekens CH (1995) Implications of small reductions in diastolic bloodpressure for primary prevention. Arch Intern Med 155, 701-709.

37. Yang YC, Lu FH, Wu JS, Wu CH \& Chang CJ (2004) The protective effect of habitual tea consumption on hypertension. Arch Intern Med 164, 1534-1540.

38. Henry JP \& Stephenslarson P (1984) Reduction of chronic psychosocial hypertension in mice by decaffeinated tea. Hypertension 6, 437-444.

39. Negishi H, Xu JW, Ikeda K, Njelekela M, Nara Y \& Yamori Y (2004) Black and green tea polyphenols attenuate blood pressure increases in stroke-prone spontaneously hypertensive rats. J Nutr 134, 38-42.

40. Lorenz M, Wessler S, Follmann E, Michaelis W, Dusterhoft T, Baumann G, Stangl K \& Stangl V (2004) A constituent of green tea, epigallocatechin-3-gallate, activates endothelial nitric oxide synthase by a phosphatidylinositol-3-OH-kinase-, cAMP-dependent protein kinase-, and Akt-dependent pathway and leads to endothelial-dependent vasorelaxation. J Biol Chem 279, 6190-6195.

41. Persson IA, Josefsson M, Persson K \& Andersson RG (2006) Tea flavanols inhibit angiotensin-converting enzyme activity and increase nitric oxide production in human endothelial cells. J Pharm Pharmacol 58, 1139-1144.

42. Kim JA, Formoso G, Li YH, Potenza MA, Marasciulo FL, Montagnani M \& Quon MJ (2007) Epigallocatechin gallate, a green tea polyphenol, mediates NO-dependent vasodilation using signaling pathways in vascular endothelium requiring reactive oxygen species and Fyn. J Biol Chem 282, 13736-13745.

43. Kim F, Tysseling KA, Rice J, Gallis B, Haji L, Giachelli CM, Raines EW, Corson MA \& Schwartz MW (2005) Activation of IKK beta by glucose is necessary and sufficient to impair insulin signaling and nitric oxide production in endothelial cells. J Mol Cell Cardiol 39, 327-334.

44. Kim F, Tysseling KA, Rice J, et al. (2005) Free fatty acid impairment of nitric oxide production in endothelial cells is mediated by IKK beta. Arterioscler Thromb Vasc Biol 25, 989-994.

45. Pan MH, Lin-Shiau SY, Ho CT, Lin JH \& Lin JK (2000) Suppression of lipopolysaccharide-induced nuclear factor-kappa B activity by theaflavin-3,3'-digallate from black tea and other polyphenols through down-regulation of I kappa B kinase activity in macrophages. Biochem Pharmacol 59, 357-367.

46. Tang WJ, Hu CP, Chen MF, Deng PY \& Li YJ (2006) Epigallocatechin gallate preserves endothelial function by reducing the endogenous nitric oxide synthase inhibitor level. Can J Physiol Pharm 84, 163-171.

47. Widlansky ME, Hamburg NM, Anter E, Holbrook M, Kahn DF, Elliott JG, Keaney JF \& Vita JA (2007) Acute EGCG supplementation reverses endothelial dysfunction in patients with coronary artery disease. J Am Coll Nutr 26, 95-102.

48. Kim W, Jeong MH, Hong YJ, Ahn YK, Kim JH, Cho JG \& Kang JC (2006) The effect of green tea on endothelial dysfunction and circulating endothelial progenitor cells in the chronic smoker. Am J Cardiol 97, 60D.

49. Nagaya $\mathrm{N}$, Yamamoto $\mathrm{H}$, Uematsu $\mathrm{M}$, Itoh $\mathrm{T}$, Nakagawa $\mathrm{K}$ Miyazawa T, Kangawa K \& Miyatake K (2004) Green tea reverses endothelial dysfunction in healthy smokers. Heart $\mathbf{9 0}$, $1485-1486$.

50. Heiss C, Schroeter H, Balzer J, Kleinbongard P, Matern S, Sies H \& Kelm M (2006) Endothelial function, nitric oxide, and cocoa flavanols. J Cardiovasc Pharm 47, S128-S135. 
51. Suganuma M, Okabe S, Oniyama M, Tada Y, Ito H \& Fujiki $H$ (1998) Wide distribution of [H-3](-)-epigallocatechin gallate, a cancer preventive tea polyphenol, in mouse tissue. Carcinogenesis 19, 1771-1776.

52. Paladini AC, Marder M, Viola H, Wolfman C, Wasowski C \& Medina JH (1999) Flavonoids and the central nervous system: from forgotten factors to potent anxiolytic compounds. J Pharm Pharmacol 51, 519-526.

53. Steptoe A, Gibson EL, Vounonvirta R, Williams ED, Hamer M, Rycroft JA, Erusalimsky JD \& Wardle J (2007) The effects of tea on psychophysiological stress responsivity and post-stress recovery: a randomised double-blind trial. Psychopharmacology 190, $81-89$.

54. Grassi D, Lippi C, Necozione S, Desideri G \& Ferri C (2007) Short administration of dark chocolate is followed by a significant increase in insulin sensitivity and a decrease in blood pressure in healthy persons. Am J Clin Nutr 81, 611-614.

55. Grassi D, Necozione S, Lippi C, Croce G, Valeri L, Pasqualetti P, Desideri G, Blumberg JB \& Ferri C (2005) Cocoa reduces blood pressure and insulin resistance and improves endothelium-dependent vasodilation in hypertensives. Hypertension 46, 398-405. 